\title{
ENTOMOLOGY
}

\section{Identification of mosquito species and determination of population density in the Taif governorate, Saudi Arabia}

\author{
T.S. Alghamdi, ${ }^{1}$ M.R. Al Zahrani, ${ }^{2}$ F.N. Gharsan, ${ }^{1}$ K.M. Al Ghamdi, ${ }^{2}$ J.A. Mahyoub ${ }^{2}$ \\ ${ }^{1}$ Biology Department, Faculty of Sciences, Al-Baha University, Al-Baha; ${ }^{2}$ Biology Department, Faculty of Sciences, \\ King Abdulaziz University, Jeddah, Saudi Arabia
}

\begin{abstract}
The surveillance of mosquitoes is the primary method for protecting humans from the spread of dangerous diseases such as malaria and dengue fever transmitted by certain mosquito species. The present study aimed to survey and identify mosquito species in the Taif governorate to determine their medical importance and monitor their distribution across seasons. A black hole light trap was used to collect adult mosquitoes, with four readings per month over an entire year recorded. A total of 3796 adult mosquitoes were collected, and 12 species were identified. All species belonged to the following genera: Culex, Aedes, Anopheles, Culiseta, and Lutzia; however, mosquito genera of medical importance (i.e., Culex, Aedes, and Anopheles) were examined in the
\end{abstract}

Correspondence: Tariq Saeed Alghamdi, Biology Department, Faculty of Sciences, Al-Baha University, Al-Baha, Saudi Arabia,

Tel.: +966553874772

E-mail:msaa1258@gmail.com

Key words: Taxonomy, Seasonal fluctuation, Mosquitoes species, Density, Climate.

Acknowledgements: The authors would like to thank the Research Unit of Dengue Fever and Vector Control team, King Abdulaziz University, for their support and providing the facilities to complete this research.

Contributions: The authors contributed equally.

Conflict of interest: The authors declare no potential conflict of interest.

Funding: None.

Received for publication: 8 August 2020.

Revision received: 23 February 2021.

Accepted for publication: 26 February 2021.

${ }^{\circ}$ Copyright: the Author(s), 2021

Licensee PAGEPress, Italy

Journal of Entomological and Acarological Research 2021; 53:9303 doi:10.4081/jear.2021.9303

This article is distributed under the terms of the Creative Commons Attribution Noncommercial License (by-nc 4.0) which permits any noncommercial use, distribution, and reproduction in any medium, provided the original author(s) and source are credited. present study. Adult mosquito species occurred throughout the entire year, with peaks of density and activity during summer and autumn $\left(24-30^{\circ} \mathrm{C}\right)$, confirming that environmental temperature plays a key role in mosquito existence and distribution. This study might provide evidence regarding the spread of mosquitoes and creates a database of the mosquito species in the Taif governorate, which would assist in pest control programs.

\section{Introduction}

Mosquitoes are the main vectors of various diseases to humans, such as malaria, dengue, filaria, and Zika fever (Pavela and Benelli, 2016). Mosquitoes can live in diverse environments and have an almost global reach (Rueda, 2007). Conducting surveys and investigating seasonal fluctuations of mosquito species, especially those of medical importance, are typical methods for mitigating risks to humans and animals caused by such species. The survey method collects essential information regarding the density of different mosquito species, and helps decrease the quantity of pesticides sprayed randomly in the environment (Mahyoub, 2011). The distribution and identification of mosquitoes have been studied by many researchers in Saudi Arabia. For example, Alikhan et al. (2014) and Al-Ghamdi et al. (2008) recorded four Aedes species and 11 Anopheles species, respectively, from Jeddah and its satellite town. Mattingly and Knight (1956) conducted a study covering the eastern, western, and southern regions of Saudi Arabia and recorded 25 species and sub-species, including Aedes aegypti, Ae. arabiensis, Ae. caspius, Anopheles cinereus, An. coustani, An. fluviatilis, An. Sergentii, An. gambiae, An. multicolor, An. pharoensis, An. stephensi, An. pulcherrimus, An. turkhudi, Culex sitiens, Cx. pipiens molestus, Cx. pipiens fatigans, Cx. pusillus, Cx. sinaiticus, Cx. laticinctus, Cx. tritaeniorhynchus, Cx. tigripes, and Culiseta longiareolata. Büttiker (1981) found that the most prevalent mosquito in Saudi Arabia was Cx. pipiens. Abdullah and Merdan (1995) recorded nine species of mosquitoes in the southwestern region of Saudi Aribia, including An. multicolor, An. arabiensis, and C. subochrea. ElKhereji et al. (2007) studied the spread of mosquitoes in Riyadh and recorded 15 species, including Ae. caspius, An. stephensi, An. coustani, An. dthali, An. pretoriensis, Cx. laticinctus, Cx. perexiguus, $C x$. pipiens, $C x$. quinquefasciatus, $C x$. simpsoni, $C x$. sinaiticus, $C x$. theileri, $C x$. tritaeniorhynchus, $C x$. univittatus, and $C$. longiareolata. Nine species were recorded in Jeddah by Mahyoub et al. (2013), including Ae. aegypti, Ae. caspius, Cx. quinquefas- 
ciatus, Cx. tritaeniorhynchus, An. gambiae, An. sergentii, An. pharoensis, and An. dthali. Alahmed et al. (2009) recorded 19 species belonging to four genera: Culex, Aedes, Anopheles, and Culiseta, with $C x$. arbieeni reported for the first time in the Taif province.

Field studies have included monitoring the seasonal activity of mosquitoes. Reiter (2001) stated that the activity, behavior, and survival of mosquitoes and the mechanics of their transmission of pathogens are strongly influenced by climatic factors such as temperature, humidity, wind, and rainfall. A warm environment and high rainfall help mosquitoes to complete their life stages and accelerate the growth of pathogens carried by mosquitoes (Hales et al., 2002; Shaman and Day, 2007). In the Jeddah governorate, AlGhamdi et al. (2008) found that the seasonal abundance of Aedes mosquitoes in January was affected by an average temperature of $23^{\circ} \mathrm{C}$ and relative humidity of $55 \%$, and showed a significant correlation between high relative humidity and increased mosquito population. Mahyoub et al. (2015) conducted another study in Makkah and these authors found that the mosquito genus with the highest density was Culex (95\%) in February at a temperature of $25.6^{\circ} \mathrm{C}$ and relative humidity of approximately $54 \%$, followed by Aedes and Anopheles.

The present study aimed to conduct a widespread survey of mosquitoes in the Taif governorate to identify mosquito species and determine the female-to-male ratio. In addition, this study aimed to investigate the effects of climatic conditions on the density and activity of mosquitoes.

\section{Materials and Methods}

\section{Field study}

The field study, conducted from January 2018 to December 2018 in the Taif governorate, revealed the presence of many mosquito species, especially those of medical importance, which were found continuously throughout the year.

\section{Study area and survey of adult mosquitoes}

The Taif governorate is one of the main tourist attractions in the Kingdom of Saudi Arabia, located in the southeast of the Makkah region on the eastern slopes of the Sarawat Mountains at an altitude of $1,700 \mathrm{~m}$ above sea level with coordinates of $21^{\circ} 16^{\prime} 30.34^{\prime \prime} \mathrm{N} 40^{\circ} 24^{\prime} 22.16^{\prime \prime} \mathrm{E}$.

Adult mosquito samples were collected using black hole light traps (Bio-Trap, Gangnam-Gu, Seoul, 135-744, South Korea) once a week at a rate of four readings per month over an entire year. A total of 10 traps were used for the study, and two traps were placed at each site. The traps were hung at a height of almost $1.5 \mathrm{~m}$ from the ground, because these traps can be tampered with and their suction fan works more effectively when it is off the ground. The main feature of this trap is the metal part surrounding the fan, which is coated with titanium dioxide $\left(\mathrm{TiO}_{2}\right)$. The heat emitted from fluorescent lamps (ultraviolet rays) reacts with $\mathrm{TiO}_{2}$ to produce carbon dioxide $\left(\mathrm{CO}_{2}\right)$, creating conditions similar to the human body and attracting mosquitoes close to the light trap. Ultimately, the mosquitoes were captured by the blow fan.

Five sites (central, north, south, west, and east) in the Taif governorate were selected to cover the majority of the study area, and represented different mosquito breeding sites, including parks, mosque toilets, drainages, marble factory, farms, brick factory, road bridges, and rainwater sites (Table 1). The traps were hung during the pre-sunset period (4-6 pm) and were collected the following morning (6-8 am), once a week for an entire year, with four readings per month. These times were chosen because they represent the active period of mosquitoes when they are searching for food. The trap containers were emptied of mosquitoes and placed inside independent plastic boxes, and labeled with the relevant data (site name and collection date). The samples were then taken to the Research Unit of Dengue Fever and Vector Control at King Abdulaziz University, where they were placed in a freezer for $1 \mathrm{~h}$ to kill the live insects before being removed and left at room temperature for $1 \mathrm{~h}$ to relax the muscles of the mosquitoes.

The mosquitoes were identified to genus and species using specialized taxonomic dichotomic keys (Barraud, 1934; Harbach and Knight, 1980; Reinert, 2000; Azzam, 2006). The samples were sorted by sex to determine the female-to-male ratio, which was calculated using Microsoft Excel 2010. Climate data, including temperature, relative humidity, and rainfall during the study period, were obtained from the General Authority of Meteorology and Environmental Protection. Pearson's correlation coefficient was calculated to determine the correlation between environmental factors and mosquito populations to calculate the influence of these factors on mosquito activity and to determine the active periods throughout the year in the Taif governorate.

The SPSS software program (version 25) was used for data analysis with one-way analysis of variance. Differences were considered significant at $p<0.05$. The relationships among temperature, humidity, rainfall, and mosquito density were determined using the Pearson's correlation coefficient.

\section{Results}

\section{Survey and identification of adult mosquito species}

A total of 3796 adult mosquitoes were collected across the study sites; these mosquitoes belonged to the main mosquito genera of vector diseases (i.e., Aedes, Culex, and Anopheles). A total of 12 mosquito species in the Taif governorate were classified based on their morphological characters. Two species belonged to the genus Anopheles, one species to the genus Aedes, and nine species belonged to the genus Culex (Table 2). Other species were found (e.g., Lutzia spp. and Culiseta spp.); however, these species did not have medical importance and were irrelevant to the present study.

\section{Female-to-male ratio of mosquito density}

The number of female mosquitoes collected by the light traps was higher than males for all genera during the study period, with 2856 females collected $(75.23 \%)$ and 940 males $(24.76 \%)$. The

Table 1. Coordinates of the mosquito study sites in Taif governorate using a GPS system.

\begin{tabular}{lllc} 
Region & Location Description & \multicolumn{2}{c}{ Coordinates } \\
& & N & E \\
\multirow{2}{*}{ North of Taif } & Mall & $21^{\circ} 21.346^{\prime}$ & $40^{\circ} 30.095^{\prime}$ \\
& Mosque toilets & $21^{\circ} 26.437^{\prime}$ & $40^{\circ} 30.067^{\prime}$ \\
\multirow{2}{*}{ East of Taif } & Workers' house & $21^{\circ} 16.914^{\prime}$ & $40^{\circ} 26.618^{\prime}$ \\
& Brick factory & $21^{\circ} 16.872^{\prime}$ & $40^{\circ} 26.455^{\prime}$ \\
\hline Center of Taif & King Abdullah Park & $21^{\circ} 16.344^{\prime}$ & $40^{\circ} 24.488^{\prime}$ \\
& Butchery & $21^{\circ} 16.370^{\prime}$ & $40^{\circ} 24.311^{\prime}$ \\
\multirow{2}{*}{ West of Taif } & Farm & $21^{\circ} 20.492^{\prime}$ & $40^{\circ} 25.766^{\prime}$ \\
& Old mosque & $21^{\circ} 19.576^{\prime}$ & $40^{\circ} 26.749^{\prime}$ \\
\hline South of Taif & Marble factory & $21^{\circ} 15.299^{\prime}$ & $40^{\circ} 27.501^{\prime}$ \\
& Agricultural Nursery & $21^{\circ} 14.576^{\prime}$ & $40^{\circ} 26.368^{\prime}$ \\
\hline
\end{tabular}


differences between the sexes were highly significant in the genus Culex $(p=0.0065)$ and the genus Anopheles $(p=0.0415)$, whereas there was no significant difference between females and males in the genus Aedes ( $\mathrm{p}=0.5762$, Table 3 ).

\section{Density of mosquitoes per months during the study year}

Culex, Anopheles, and Aedes were present throughout the year; however, they were found at different rates. For the mean monthly population density values, there were significant differences for Culex $(\mathrm{X}=74.875 \pm 11.372, \mathrm{p}=0.0001)$ and Aedes $(\mathrm{X}=3.395 \pm 0.763$, $\mathrm{p}=0.0001)$, whereas for Anopheles $(\mathrm{X}=2.583 \pm 0.927)$, no significant differences were found $(\mathrm{p}=0.3912)$.

The study showed significant differences in the population density of genus Aedes during the year, with a peak intensity in November $(X=15 \pm 1.95$ with a significant difference $(p<0.05)$, whereas the lowest values were recorded in February, April, and May $(X=1 \pm 0.00)$. The study recorded a moderate population density for this genus during August, July, and September (7.5 \pm 3.013 , $5 \pm 1.47$, and $2.25 \pm 0.75$, respectively), and a low population density during January, March, June, October, and December (1.75 \pm 0.47 , $1.75 \pm 0.47,1.75 \pm 0.47,1.5 \pm 0.28$, and $1.25 \pm 0.25$, respectively, Figure 1 and Table 4). The results of the statistical analysis showed significant differences among months $(\mathrm{p}=0.0001)$.

The population density of Culex was higher than that of Aedes and Anopheles, representing $92.6 \%$ of the total collected species of medical importance during the study period. The highest population density was recorded in June $(X=187 \pm 26.02)$, whereas the lowest population density was found in February $(X=20 \pm 6.75)$. A moderate population density was recorded during August, September, and November, with highly significant differences between months ( $\mathrm{p}=0.0001$, Figure 2 and Table 4). Anopheles had the lowest population density of all three genera (3.29\%), with its highest population density recorded in September $(X=4.75 \pm 1.9)$, whereas the lowest density was recorded in February $(X=1 \pm 0.00)$ and a moderate density was recorded during May, June, and November, with no significant differences between months $(p=0.3912$, Figure 3 and Table 4$)$

\section{Seasonal activity and dynamic fluctuation of mosquitoes in the Taif governorate}

The results showed the presence of genera of medical impor-

Table 2. Registered mosquito species in the Taif governorate during the study period.

\begin{tabular}{lll} 
No. & Genus & Species \\
1 & Aedes (Ae.) & aegypti \\
2 & Culex $(C x$. $)$ & perexiguus \\
& & theileri \\
& laticinctus \\
& poicilipes \\
& quinquefasciatus \\
& pipiens \\
& sitiens \\
& univittatus \\
& sinaiticus \\
& & dthali \\
& & arabiensis \\
\hline 3 &
\end{tabular}

Table 3. Comparison of the means and standard errors (SE) between male and female Culex, Anopheles, and Aedes mosquitoes in the Taif governorate.

\begin{tabular}{lcccc} 
Genus & Male $\left({ }^{3}\right)$ & Female $(+)$ & Means \pm SE & P value \\
Culex & $69.583 \pm 10.421^{\mathrm{a}}$ & $223.416 \pm 50.04^{\mathrm{b}}$ & 106.02 & 0.0065 \\
Anopheles & $3.5 \pm 0.75^{\mathrm{a}}$ & $7 \pm 4.30^{\mathrm{b}}$ & 3.352 & 0.0415 \\
\hline Aedes & $5.50 \pm 2.22^{\mathrm{a}}$ & $7.5 \pm 2.73^{\mathrm{a}}$ & 7.31 & 0.576 \\
\hline
\end{tabular}

*Means followed by the same letters in the same row showed no significant differences at $\mathrm{p}<0.05$. Degrees of freedom $=22 ; \mathrm{LSD}=$ Least significant difference.

Table 4. Population means and standard errors (SE) of adult Culex, Anopheles, and Aedes in the Taif governorate during the study period.

\begin{tabular}{|c|c|c|c|c|c|c|}
\hline \multirow[t]{2}{*}{ Month } & \multicolumn{6}{|c|}{ Means \pm SE } \\
\hline & Culex & Aedes & Anopheles & Temp. $\left({ }^{\circ} \mathrm{C}\right)$ & Rh \% & Rf mm \\
\hline January & $52.25 \pm 10.61^{\text {cde }}$ & $1.75 \pm 0.478^{\mathrm{cd}}$ & $1.75 \pm 0.75^{\mathrm{abc}}$ & $14.75 \pm 0.629^{\mathrm{e}}$ & $48.5 \pm 3.926^{\mathrm{bc}}$ & $1 \pm 0^{\mathrm{b}}$ \\
\hline February & $20 \pm 6.75^{\mathrm{e}}$ & $1 \pm 0.00^{\mathrm{d}}$ & $1 \pm 0.00^{c}$ & $16.25 \pm 0.75^{\mathrm{e}}$ & $54.5 \pm 1.5^{\mathrm{ab}}$ & $1.75 \pm 0.478^{b}$ \\
\hline March & $35.50 \pm 4.83^{\mathrm{de}}$ & $1.75 \pm 0.478^{\mathrm{cd}}$ & $1.75 \pm 0.478^{\mathrm{abc}}$ & $21 \pm 0.408^{d}$ & $46.75 \pm 3.19^{\mathrm{bc}}$ & $1.25 \pm 0.25^{b}$ \\
\hline April & $35.75 \pm 11.49 \mathrm{de}$ & $1 \pm 0.00^{\mathrm{d}}$ & $2 \pm 0.577 \mathrm{abc}$ & $24.75 \pm 0.478^{c}$ & $35.5 \pm 2.327^{\mathrm{de}}$ & $11.25 \pm 10.3^{\mathrm{ab}}$ \\
\hline May & $82 \pm 11.60^{c}$ & $1 \pm 0.00^{\mathrm{d}}$ & $3.25 \pm 1.314^{\mathrm{abc}}$ & $24.75 \pm 2.13^{\mathrm{c}}$ & $44.5 \pm 5.979 \mathrm{~cd}$ & $13.5 \pm 7.55^{\mathrm{a}}$ \\
\hline June & $187 \pm 26.02^{\mathrm{a}}$ & $1.75 \pm 0.478^{\mathrm{cd}}$ & $3.5 \pm 1.50^{\mathrm{abc}}$ & $31.25 \pm 0.478^{b}$ & $22 \pm 1.08^{f}$ & $1 \pm 0^{\mathrm{b}}$ \\
\hline July & $65 \pm 9.69^{\text {cd }}$ & $5 \pm 1.471^{\mathrm{bc}}$ & $1.5 \pm 0.50^{\mathrm{bc}}$ & $30.75 \pm 0.629^{b}$ & $21.25 \pm 0.63^{f}$ & $1.5 \pm 0.5^{b}$ \\
\hline August & $51.75 \pm 12.80^{\text {cde }}$ & $7.5 \pm 3.013^{\mathrm{b}}$ & $1.75 \pm 0.478^{\mathrm{abc}}$ & $30.5 \pm 0.288^{b}$ & $33.75 \pm 1.10^{\mathrm{e}}$ & $4 \pm 1.77^{\mathrm{ab}}$ \\
\hline September & $55 \pm 9.83$ cde & $2.25 \pm 0.75^{\mathrm{cd}}$ & $4.75 \pm 1.93^{\mathrm{a}}$ & $37 \pm 0.408^{a}$ & $60.25 \pm 5.71^{\mathrm{a}}$ & $2 \pm 0^{\mathrm{b}}$ \\
\hline October & $118.75 \pm 8.34^{b}$ & $1.5 \pm 0.288^{\mathrm{d}}$ & $2.5 \pm 0.645^{\mathrm{abc}}$ & $24.5 \pm 0.288^{c}$ & $31.75 \pm 3.03^{\mathrm{e}}$ & $1.25 \pm 0.25^{b}$ \\
\hline November & $171 \pm 17.85^{\mathrm{a}}$ & $15 \pm 1.95^{\mathrm{a}}$ & $3 \pm 0.816^{\mathrm{abc}}$ & $24.5 \pm 1.55^{c}$ & $46 \pm 3.31^{\mathrm{bc}}$ & $6.75 \pm 3.614^{\mathrm{ab}}$ \\
\hline December & $24.5 \pm 6.66^{\mathrm{e}}$ & $1.25 \pm 0.25^{\mathrm{d}}$ & $4.25 \pm 2.136^{\mathrm{ab}}$ & $16.5 \pm 0.5^{\mathrm{e}}$ & $45.5 \pm 3.593^{\mathrm{bc}}$ & $6.5 \pm 3.403^{\mathrm{ab}}$ \\
\hline Pvalue & 0.0001 & 0.0001 & 0.3912 & 0.0001 & 0.0001 & 0.342 \\
\hline
\end{tabular}


tance (Aedes spp., Culex spp., and Anopheles spp.) over the study year. However, the population density varied with climatic changes. The temperature affected the activity and intensity of mosquitoes. There was a significant positive correlation between the temperature and the different genera $(\mathrm{r}=0.351, \mathrm{p}=0.0001)$, with the highest population density of Aedes spp. in November

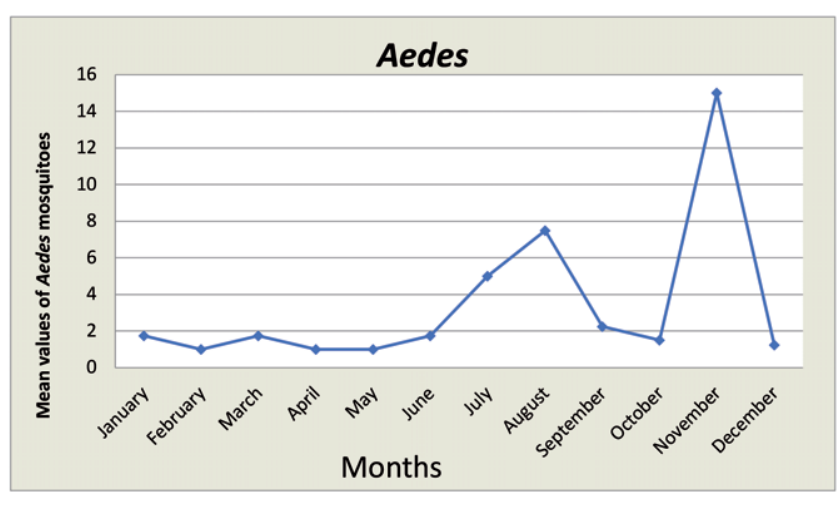

Figure 1. Mean values of Aedes mosquitoes during the study period in the Taif governorate.

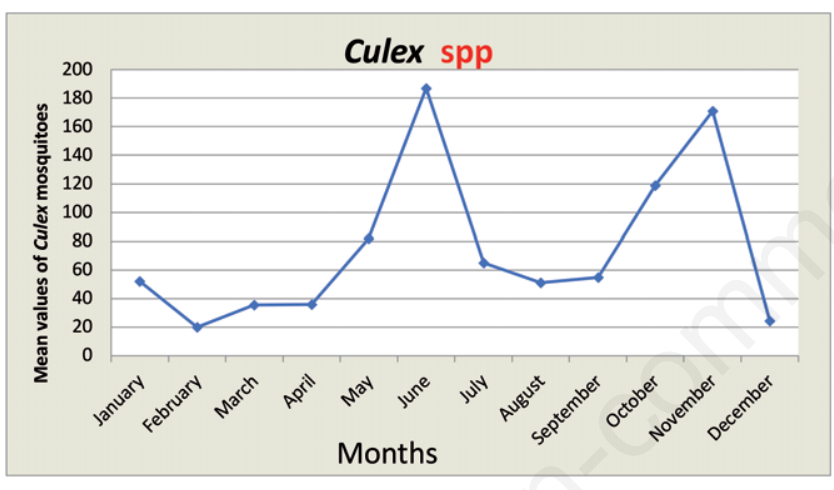

Figure 2. Mean values of Culex mosquitoes during the study period in the Taif governorate.

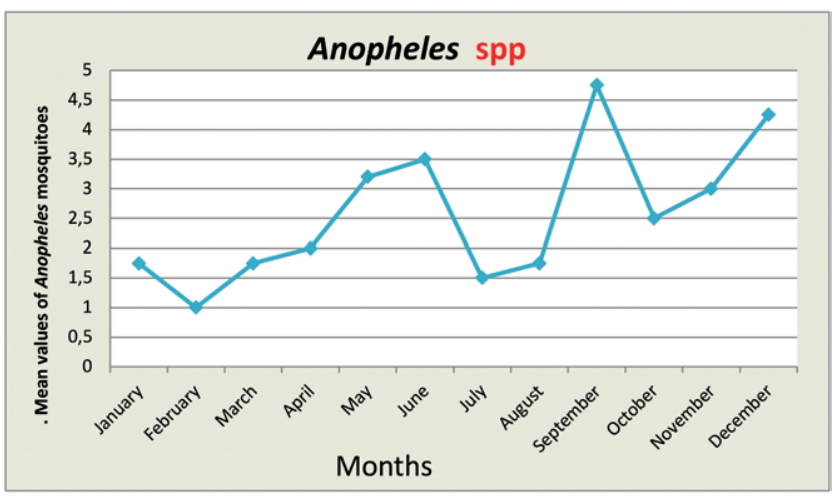

Figure 3. Mean values of Anopheles mosquitoes during the study period in the Taif governorate.
$(\mathrm{X}=15 \pm 1.950)$ that had a high temperature average $\left(X=24.5 \pm 1.55^{\circ} \mathrm{C}\right)$. Culex spp. recorded the highest density in June $(\mathrm{X}=187 \pm 26.02)$ that had a high temperature average $\left(\mathrm{X}=31.25 \pm 0.478^{\circ} \mathrm{C}\right)$. The lowest mosquito density was recorded in February that had an average temperature $\left(X=16.25 \pm 0.75^{\circ} \mathrm{C}\right)$. Anopheles spp. recorded the highest density in September $(X=4.75 \pm 1.93)$ at a high temperature average $\left(X=37 \pm 0.408^{\circ} \mathrm{C}\right)$, whereas the lowest density was recorded in February that had a low temperature average $\left(\mathrm{X}=16.25 \pm 0.75^{\circ} \mathrm{C}\right)$ (Figures 4-7). However, the relative humidity and rainfall showed no significant effect on the population density of mosquitoes. There was a negative correlation with the value of $r=-0.114$ and $r=-0.0469$, respectively, with no regular increase in the number of mosquitoes noted when the relative humidity and rainfall increased compared to temperature (Table 4).

\section{Discussion}

In the present study, black hole light traps were used to collect adult mosquitoes. This trap has greater effectiveness in catching mosquitoes than other traps such as CDC miniature light traps (Clarke Mosquito Control, Roselle, IL), which require dry ice around the trap as the $\mathrm{CO}_{2}$ source and need to have their batteries charged. The black hole light trap is an eco-friendly trap and it has proven effectiveness in catching mosquitoes from previous studies (Al-Ghamdi et al., 2008; Alikhan et al., 2014). A total of 3796 mosquito adults were collected, and 12 species were identified in the Taif governorate in the present study. These species included Cx. perexiguus, Cx. theileri, Cx. laticinctus, Cx. poicilipes, Cx. quinquefasciatus, $C x$. pipiens, $C x$. sitiens, Cx. univittatus, $C x$. sinaiticus, An. dthali, An arabiensis, and Ae. aegypti. Culiseta spp. and Lutzia spp. were also present. The three genera Aedes, Culex, and Anopheles are of greater medical importance in Saudi Arabia than genera Lutzia and Culiseta. However, Culiseta spp. does have veterinary importance and can transmit other diseases to humans, such as the encephalitis virus, in other parts of the world (Edman et al., 1972).

The species found in the present study are similar to those found in previous field studies. For example, Alahmed et al. (2009) recorded 19 species, Mahyoub et al. (2013) recorded nine species in Jeddah, located northwest of Taif Therefore, all species recorded in the present study have been found in other regions of the Kingdom. However, it was essential to perform this survey to iden-

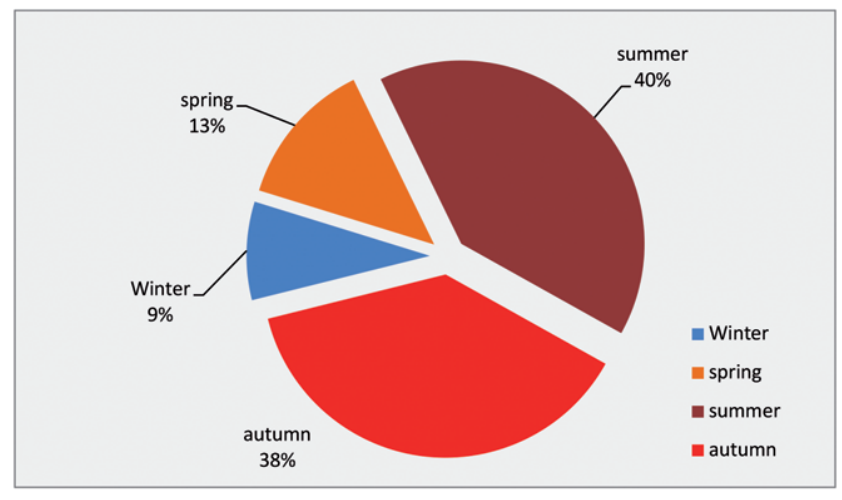

Figure 4. Percentage of seasonal population density of mosquito species of medical importance in the Taif governorate. 
tify the species of medical importance, such as $A$. aegypti, which is considered the main vector of dengue fever, and such identification will help in future mosquito control and management programs.

The increase in species density was due to varying environments and weather conditions. The most abundant genus was Culex, which comprised $92.6 \%$ of the total collected mosquito

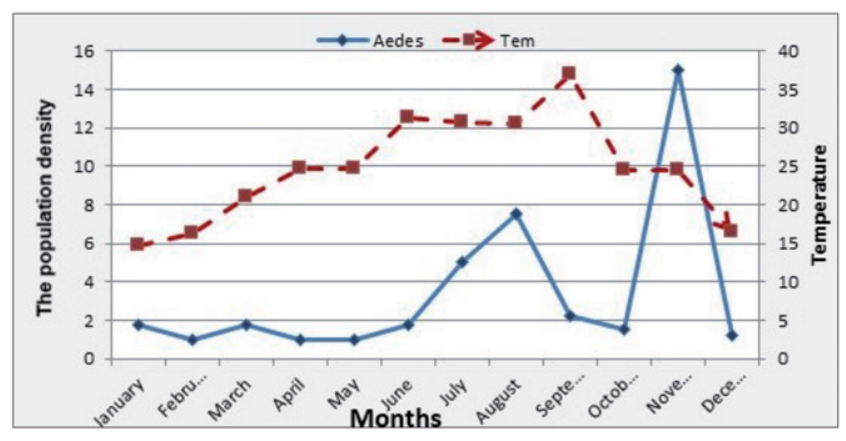

Figure 5. Relationship between temperature means and population density of adult Aedes during the study period.

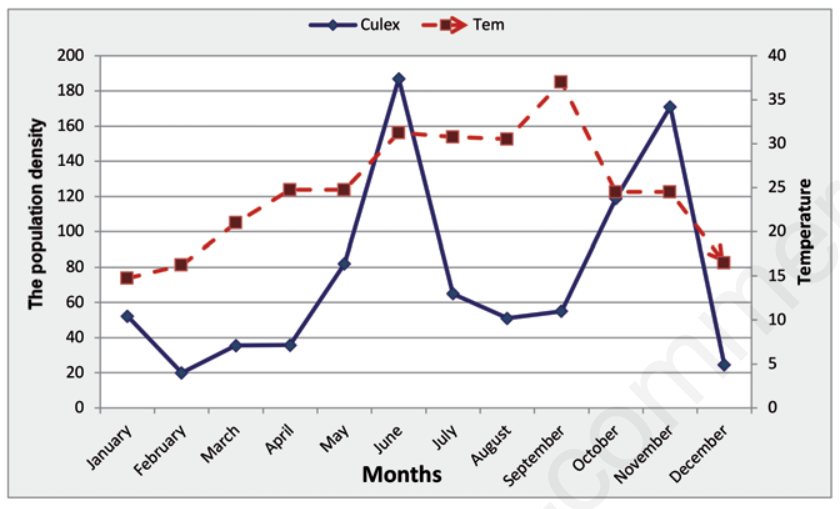

Figure 6. Relationship between temperature means and population density of adult Culex during the study period.

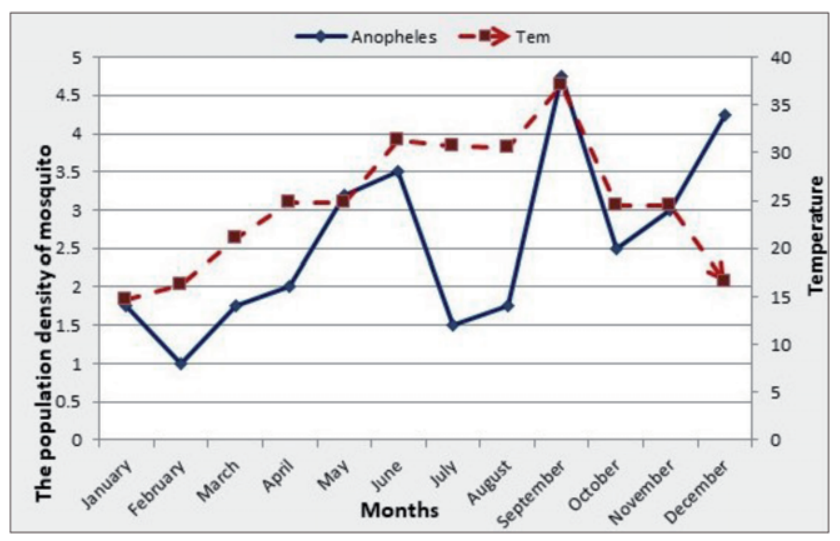

Figure 7. Relationship between temperature means and population density of adult Anopheles during the study period. species during the collection period. The survey results showed that the ratio of mosquito females $(75.23 \%)$ collected by light traps was higher than that of males $(24.76 \%)$. Similar observations were recorded in another study conducted in the Baljurashi governorate when a black hole light trap was used (Alghamdi, 2018). The percentage of females collected by Clark traps was approximately $98 \%$ in a field study conducted in the Jeddah governorate (Alqhtani, 2009). CDC light traps showed that the female-to-male ratio was 15.7:1 during a study conducted in the city of Makkah (Khater et al., 2013). The black hole trap is designed to produce $\mathrm{CO}_{2}$, which is important for the attraction of female mosquitoes. Females travel great distances from breeding sites seeking hosts during the day, making them more likely to fall into traps. However, the black hole trap can also catch males, which is attributed to the presence of a fluorescent lamp, nearness of the trap to breeding sites, and males flying with females around the trap for reproduction. These observations are in agreeance to other studies that were performed in Riyadh, Makkah, Madinah Al munwwrah, Najran, Jeddah, and the eastern region of Saudi Arabia (El-Khereji et al., 2007; Alahmed et al., 2009; Alahmed et al., 2010; Kheir et al., 2010; Mahyoub et al., 2013; Alahmed et al., 2015).

Temperature had a more significant effect on the presence of mosquitoes than other climatic conditions. A peak in density and activity was observed when the temperature was between 24 and $37^{\circ} \mathrm{C}$, corresponding to temperatures recorded during previous studies in several regions of Saudi Arabia (Al-Ghamdi et al., 2009; Alahmed, 2012; Hassan et al., 2017, Khan et al., 2018). There was an increase in activity and density of mosquitoes during summer and autumn in the present study, which was consistent with the study by Soltani and Keshavarzi (2016) conducted in Iran, and showed the highest mosquito density recorded in July. Relative humidity did not significantly affect mosquito density, which might be due to its association with temperature, i.e., when the temperature decreased, there was usually a large increase in the relative humidity. This result did not correspond with previous studies, which found that the increase in relative humidity in the coastal and warm areas of the Kingdom, especially during summer, played an important role in increasing the density, activity, and mating of mosquitoes. This difference might be due to the role of the relative humidity in moistening the air and decreasing the temperature, thereby protecting mosquitoes from lethal temperatures (Yamana and Eltahir, 2013; Al-Ghamdi et al., 2009).

The rainfall rate did not significantly influence the collection of the highest number of adult mosquitoes, although rain does play an important role in mosquito breeding and reproduction (Alahmed, 2012). However, during higher rainfall in the present study, adult mosquito activity decreased at all study sites, and the opportunity to catch mosquitoes in the light traps was limited. These environmental conditions might vary between field studies. The monitoring and identification of mosquitoes performed during the present study will help develop pest control programs and limit the transmission of diseases to the Taif governorate residents.

\section{Conclusions}

The present study is the first comprehensive field study of adult mosquito species, focused on the Taif governorate and mosquito species belonging to five genera, Culex, Aedes, Anopheles, Culiseta, and Lutzia, were recorded. Cx. poicilipes, Cx. sitiens, An. arabiensis, and Lutzia spp. were recorded for the first time in the Taif governorate. The highest density of mosquitoes was observed during summer and autumn, with the temperature playing a primary role in the 
spread of mosquitoes. Molecular techniques should be applied in future studies to accurately identify sibling species and morphological methods performed to contribute to the success of the control plan and reduce serious diseases caused by mosquitoes.

\section{References}

ABDULLAH M.A., MERDAN A.I., 1995 - Distribution and ecology of the mosquito fauna in the southwestern Saudi Arabia. J. Egypt. Soc. Parasitol. 25: 815-837.

ALAHMED A.M., Al KURIJI M. A., KHEIR S. M., ALAHMEDI S. A., Al HATABBI M.J. Al GASHMARI M.A., 2009 Mosquito fauna (Diptera: Culicidae) and seasonal activity in Makka Al Mukarramah Region, Saudi Arabia. - J. Egypt. Soc. Parasitol. 39: 991-1013.

ALAHMED A.M., Al KURIJI M.A., KHEIR S.M., AL SOGOOR D.A., SALAMA H.A., 2010 - Distribution and seasonal abundance of mosquitoes (Diptera: Culicidae) in the Najran Region, Saudi Arabia. - Studia Dipterological. 17: 13-27.

ALAHMED A.M., 2012 - Mosquito fauna (Diptera: Culicidae) of the Eastern Region of Saudi Arabia and their seasonal abundance. - J. King. Saud. Univ. Sci. 24: 55-62.

ALAHMED A.M., NAEEM M., KHEIR S.M., SALLAM M.F., 2015 - Ecological distribution modeling of two malaria mosquito vectors using geographical information system in AlBaha Province, Kingdom of Saudi Arabia. - Pak. J. Zool. 47: 1797-1806.

ALIKHAN M., Al GHAMDI K., MAHYOUB J. A., 2014 - Aedes mosquito species in western Saudi Arabia. - J. Insect Sci. 14.

Al-GHAMDI K., ALIKHAN M., MAHYOUB J., AFIFI Z. I., 2008 - Studies on identification and population dynamics of anopheline mosquitoes from Jeddah Province of Saudi Arabia. - Biosci. Biotechnol. Res. Commun. 1: 19-24.

Al-GHAMDI K., MAHYOUB J., 2009 - Role of climatic factors in the seasonal abundance of Aedes aegypti L. and dengue fever cases in Jeddah province of Saudi Arabia. - Curre. World Environ. 4: 307.

ALGHAMDI T.S., 2018 - Study of the seasonal fluctuation of mosquitoes population with evaluation of the effectiveness of the insecticides used against the dominant species in Baljurashi Province. PhD of Sciences, Faculty of Sciences King Abdulaziz University.

AL-QAHTANI H.A., 2009 - Determination of population density of mosquitoes in the field using the Clark traps with evaluation of some insecticides against Aedes aegypti in Jeddah Governorate. $\mathrm{PhD}$ of Sciences, Faculty of Sciences King Abdulaziz University.

AZZAM M.A. 2006 - A report of the integrated control of the insects carrying Rift Valley Fever Virus in the Kingdom of Saudi Arabia. - King Abdulaziz City for Science and Technology.

BARRAUD P.J., 1934 - The fauna of British India, including Ceylon and Burma Volume V. Family Culicidae. - Tribes Megharhinini and Culicini. - Taylor and Francis.

BUTTIKER W. 1981 - Observations on urban mosquitoes in Saudi Arabia. - Fauna Saudi Arabia. 3: 472-479.

EDMAN J., WEBBER L.A., KALE H.W, 1972 - Host-feeding patterns of Florida mosquitoes II. Culiseta - J. Med. Ent. 9: 429-434.

EL-KHEREJI M. A., ALAHMED A.M., KHEIR S.M., 2007 Survey and seasonal activity of adult mosquitoes (Diptera: Culicidae) in Riyadh City, Saudi Arabia. - Agr. Food Sci. Centre Res. Bull. 152: 5-17.
HALES S., DE WET N., MAIDONALD J., WOODWARD A., 2002 - Potential effect of population and climate changes on global distribution of dengue fever: an empirical model. Lancet. 360: 830-834.

HARBACH R.E., KNIGHT K.L., 1980 - Taxonomists glossary of mosquito anatomy. - Plexus Publishing, Inc.

HASSAN M.I., KENAWY M.A., AL ASHRY H.A., SHOBRAK M., 2017 - Influence of climatic factors on the abundance of Culex pipiens and Cx. quinquefasciatus (Diptera: Culicidae) adults in the Western Coast of Saudi Arabia. - J. Entomol. Acarol. Res. 49.

KHAN M.A., ELHOSSARY S., KHAN I.A., AL ZAHRANI M.H., AL ZAHRANI F.S., AL BASHRI F.M., 2018 - The impact of climatic variables with GIS application on the abundance of medically important mosquitoes (Diptera: Culicidae) in Jeddah, Saudi Arabia.

KHATER E.I., SOWILEM M.M., SALLAM M.F., ALAHMED A.M., 2013 - Ecology and habitat characterization of mosquitoes in Saudi Arabia. Trop. Biomed. 30: 409-427.

KHEIR S.M., ALAHMED A.M., AL KURIJI M.A., AL ZUBYANI S.F., 2010 - Distribution and seasonal activity of mosquitoes in al Madinah Al Munwwrah, Saudi Arabia - J. Egypt. Soc. Parasitol. 40: 215-227.

MAHYOUB J.A., 2011 - Study of the seasonal activity and dynamic fluctuation of medically important species of mosquitoes with reference to testing the susceptibility of the dominant species to some insecticides in Jeddah. Unpublished PhD thesis, King Abdulaziz University, Saudi Arabia.

MAHYOUB J.A., GHRAMH H.A., AL-GHAMDI K.H., FAROOQI N., 2013 - The potency of Aedes species in transmitting dengue fever virus with evaluating the susceptibility of vector larval stages to some insecticides. - Egypt Acad. J. Biol. Sci. C, Physiol. Mol. Biol. 5: 109-115.

MAHYOUB J.A., AL-HARBI O.S., AL-GHAMDI K.M., MANGOUD A.A., AL-SOLAMI H.M., 2015 - Population dynamics of different mosquito genera and species in Makkah city, Saudi Arabia. - Biosci. Biotechnol. Res. Commun. 8: 116-125.

MATTINGLY P.F., KNIGHT K.L., 1956 - The mosquitoes of Arabia. I. Bulletin of the British Museum (Natural History). B. Entomology. 4.

PAVELA R., BENELLI, G., 2016 - Ethnobotanical knowledge on botanical repellents employed in the African region against mosquito vectors-a review. - Exp. Parasit. 167: 103-108.

REINERT J.F., 2000. New classification for the composite genus Aedes (Diptera: Culicidae): elevation of subgenus Ochlerotatus to generic rank, reclassification of the other subgenera, and notes on certain subgenera and species. J. Mosquito Control Ass. 16: 175-188.

REITER P., 2001 - Climate change and mosquito-borne disease. Environ. Health Persp. 109: 141-161.

RUEDA L. M., 2007 - Global diversity of mosquitoes (Insecta: Diptera: Culicidae) in freshwater. In Freshwater Animal Diversity Assessment. - Springer, Dordrecht: pp. 477-487.

SHAMAN J., DAY J.F., 2007 - Reproductive phase locking of mosquito populations in response to rainfall frequency. - PLoS One. 2.

SOLTANI Z., KESHAVARZI D., 2016 - Species composition of mosquitoes (Diptera: Culicidae) in Farashband district, southwest of Iran. - J. Entomol. Acarol. Res. 48: 372-377.

YAMANA T. K., ELTAHIR E. A., 2013 - Incorporating the effects of humidity in a mechanistic model of Anopheles gambiae mosquito population dynamics in the Sahel region of Africa. Parasit. Vectors. 6: 235. 